NBER WORKING PAPER SERIES

\title{
CAPITAL GAINS TAXATION IN AN ECONOMY WITH AN "AUSTRIAN SECTOR"
}

Daniel J. Kovenock

Michael Rothschild

Working Paper No. $\underline{758}$

NATIONAL BUREAU OF ECONOMIC RESEARCH 1050 Massachusetts Avenue

Cambridge, MA 02138

September 1981

We thank Alan Auerbach, Yves Balcer, David Bradford, Buzz Brock, Bob Haveman, Ken Judd and Eytan Sheshinski for helpful conversations. Research support from the National Science Foundation and the University of Wisconsin Graduate School is gratefully acknowledged. The research reported here is part of the NBER's research program in Taxation. Any opinions expressed are those of the authors and not those of the National Bureau of Economic Research. 


\section{CapitaI Gains Taxation in an Economy with an "Austrian Sector"}

\section{ABSTRACT}

This paper examines the effects of a proportional capital gains tax in an economy with an Austrian sector (with wine and trees) and an ordinary sector. We analyze the effect of capital gains taxation (on both an accrual and a realization basis) on the efficiency with which resources are used within the Austrian sector. Since time is the only input which can be varied in the Austrian sector this amounts to looking at the effect of capital gains taxation on the harvesting time or selling time of assets. Accrual taxation decreases the selling time of Austrian assets. Realization taxation decreases the selling time of some Austrian assets and leaves it unchanged for others. Inflation further reduces the selling time of assets taxed on an accrual basis; often, but not always, inflation increases the selling time of Austrian assets taxed on a realization basis. These results suggest that the capital gains tax can reduce the holding period of an asset. However, there is a sense in which such taxes (at least when levied on a realization basis) discourage transactions and increase holding periods. It is never profitable to change the ownership of an Austrian asset between the time of the original investment and the ultimate harvesting of the asset for final use. We examine the effect of capital gains taxation on the efficiency of the allocation of investment between sectors. No neutrality principles emerge when ordinary investment income is taxed at the same rate as capital gains income.

We also analyze the effect of the special tax treatment of capital gains at death and find that the current U.S. tax system, under which capital gains taxes are waived at death, encourages investors to hold assets longer than they otherwise would.

Michae1 Rothschild Mathematica, Inc. P.0. Box 2392 Princeton, New Jersey 08540 (609) 799-2600
Danie1 J. Kovenock Department of Economics University of Wisconsin Madison, Wisconsin 53706

(608) 262-5831 


\section{Introduction}

This paper examines the effects of a simple capital gains tax in an economy with an Austrian sector and an ordinary sector. In the ordinary sector the investment process is simple and straightforward; an investment of a dollar produces a stream of returns in the future. Assets in the Austrian sector do not yield a stream of services. They increase in value as they age; when they are harvested this growth stops. The standard examples of Austrian investments are wine and trees, and we shall use these terms to refer to two different kinds of Austrian assets. Trees are assets which require scarce resources -- i.e., ones which earn rents -while they age. In considering when to cut down a tree it is important to take account of the fact that the land on which a tree now stands can be used to grow another tree once its present occupant is felled. Wine, in distinction, uses no scarce resources as it matures; the casks and cellars in which wine ages earn no rents.

We focus on the effects of capital gains taxation on Austrian investments for two reasons. First, the effects are simple and straightforward. We are able to obtain exact expressions for the effect of capital gains taxes on the allocation of investment between sectors and for the efficiency of resource use within the Austrian sector. We extend some of this analysis to the case where the death of the investor (which has significant tax consequences in the U.S.) is uncertain. ${ }^{1}$

1 In an earlier version of this paper, we also considered the effect of uncertainty about the growth of Austrian assets; since the rain conclusion cf that exercise ins that consicering uncertainty did not change the character of our results, we have cropped it from our paper. 
Secondly, a capital gains tax affects the timing of transactions. With Austrian assets these effects have real, easily-understood consequences. Most previous studies, empirical and theoretical, ${ }^{2}$ have, implicitly or explicitly, focused on the effect of capital gains taxation on purely financial assets. It seems clear from first principles that capital gains taxes should, at least in an inflationary world, operate as a kind of turnover tax, inhibiting the sale of 'stocks and bonds which show gains and encouraging the sale of assets on which losses have been incurred. Constantinides (1980) and Constantinides and Scholes (1980) have shown just how appealing the strategy of realizing losses and never selling gains can be when well-organized futures markets with low transactions costs exist. Feldstein, slemrod, and Yitzhaki (1980), Feldstein and Slemrod (1978), and Feldstein and Yitzhaki (1978) have presented evidence that this theory is correct -that the capital gains tax does indeed inhibit the sale of assets whose prices have increased since they were purchased. It is not clear, at least to us, what the real effect of such an inhibition is. In general, sales of stock are purely financial transactions and do not lead to investment or disinvestment of real assets. While it seems quite likely that the volume of transactions has some effect on the efficiency of the allocation of investment, to our knowledge, no one has framed a theory which will allow us to detertis the preferred volume of transactions. Without such a theory one cannot say whether discouraging transactions is good or bad.

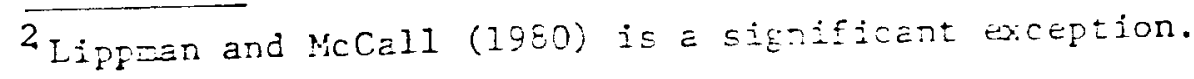


Our analysis assumes that capital gains taxes fall only on Austrian assets. Thus we can only analyze the effect of the capital gains tax on Austrian assets. The ordinary sector is in our model for two reasons; first, we assume that it is sufficiently large that the after-tax rate of return -- which in our simple model is the social discount rate -is determined outside of the Austrian sector and is independent of the rate and form of the capital gains tax. Secondly, having an ordinary sector allows us to examine the effect of capital gains taxation on the allocation of resources between Austrian and other investments.

We sumnarize our results as follows. Section I sets out the basic model and analyzes the effects of capital gains taxation on Austrian investments. Our partial equilibrium model assumes that the total amount of investment is fixed. Taxation, in particular the capital gains tax, can affect economic efficiency in two quite different ways. First taxes can affect the flow of investment between sectors. The intersectoral allocation of investment is efficient when the present discounted value of all returns -- public and private -- from a dollar of investment is the same in all sectors. We find that when income in the ordinary sector is taxed at rate $\tau_{0}$ and capital gains in the Austrian sector are taxed at rate $\tau$, this equality is unlikely to hold, even if $\tau=\tau_{0}$. In particular, when tax rates in the sectors are equal, Austrian investments have lower total returns than ordinary investrnents.

While not without interest, this comparison is quite artificial. A Twajor accomplishent of recent research on the taration of capital has been the demonstration that $\tau_{0}$ is an extraordinarily complicated beast. As the endproduct of the copplex interaction of aeny provisions of the tax law, to cannot be identified with anytins so siale as the corporate 
income tax. Thus it is hard to conceive of a realistic tax change which could set $\tau_{0}=\tau$.

Another effect of capital gains taxation is on the allocation of resources within a sector. For Austrian investments, the resource whose use can be varied is time; we find that the capital gains tax leads to inefficiencies within the wine sector by encouraging wine to be sold more quickly than it would be in the absence of taxation. This does not hold for some tree investments. If investment opportunities are stationary, and if there is no inflation, cutting time is independent of $\tau$ and capital gains taxation introduces no distortions. If conditions are not stationary, or if there is inflation, taxes affect cutting time in a complicated way.

These results were obtained for taxation on a realization basis. Accrual taxation introduces different distortions. When $\tau=\tau_{0}$ total returns from Austrian investments (both wine and trees) can be greater or less than returns from ordinary investments. For a given rate of taxation, selling time (again for wine and trees) is less under accrual taxation than under realization taxation. We have made comparisons of taxation at equal rates rather than equal yields because such comparisons are simpler. However, as Stiglitz (1981) has shown, the problem of calculating the effective yield of a capital gains tax is sufficiently complex that it seems no good case can be made for the proposition that comparisons of taxes which have equal yields are more meaningful than comparisons of taxes which have equal rates. our model produces no strong a priori case for the greater efficiency of accrual taxation. Our examination of the effects of inflation in Section II strengthens the case for realization as opposed to accrual taxation. Although there are exceptions, on balance inflation (at least rapid inflation) tends to alleviate tise distortions caused by taxation on a realization basis while it 
complicates, sometimes exacerbating and sometimes alleviating the distortions caused by accrual taxation.

In section III we show how the analysis is changed by taking account of the special ways in which capital gains are, or could be taxed, at death. We show how the present United States tax system, which allows automatic step up of basis at death, encourages people to hold on to assets longer than they would otherwise. Since the tax system leads them to sell wine sooner than they should, at least for wine this corrects (and possibly overcorrects) a distortion of the tax system.

Much previous work on capital gains taxation has focused on the way in which capital gains taxes tend to inhibit transactions and to encourage investors to hold assets -- at least assets wich are growing in value -longer than they otherwise would. Our analysis suggests that the effects are diverse and complicated. The results sumarized above showed that the capital gains tax could sometimes shorten, sometimes lengthen, and sometimes leave unchanged the length of time the owner of an Austrian asset would wait before he harvested it. However, we did obtain one result which shows that the capital gains tax discourages transactions in Austrian assets. In Proposition 3 below we show that the owner of an Austrian asset who is subject to capital gains taxation on a realization basis will never sell it to another intermediate producer. He will always make higher profits by holding on to hine until it is sold to the consumer. Although Proposition 3 is stated for wine, it also clearly holds for trees. Thus the capital gains tax acts as a kind of turnover or transaction tas on Austrian assets and as such prowotes vertical integration in industries which use Austrian processes. 
We have sacrificed a great deal of reality to keep our models simple and tractable. The capital gains tax is proportional and everyone pays the same rate. We ignore the complexities and arbitrage opportunities which are encouraged by progressive taxation at different rates. ${ }^{3}$ We also ignore the arbitrage opportunities which the options market permits. Constantinides (1980) and Constantinides and Scholes (1980) have argued that by using the options market, investors can avoid ever realizing capital gains. Sales of assets (which are taxable events) are dominated by the purchase and sale of options (based on the asset's future value) which can be written in such a way that taxes are avoided or deferred. This argument loses some of its force in an Austrian model. Assets must be sold eventually or the tree rots or the wine goes bad. Eow the existence of an active options warket would affect our results is an interesting question which we have not examined.

We have also assumed that investors have a very simple goal. They maximize the present discounted value of wealth. We assume a constant discount rate of $r$. When we treat uncertainty we assume that investors are risk yeutral so that they meximize the expected present discounted value of wealth. Thus we ignore both risk aversion and portfolio effects. We rake this choice for two reasons. First, 1t's wat we can co. Second, whlle it is not formally difficult to entroduce risk aversion into some

3 Lippman and McCall (1980) analyze a similar model in which taves are progressive. 
of our models, we are uncertain as to how to interpret the results. Suppose an Investor's portfolio contains assets which will be harvested at different dates; risk aversion is not adequately treated by assuming the same concave function values wealth recelved at each date. To handle rlsk aversion a more complex model - presumably one with consumption is needed. A further simplification is obtained by our treatment of death. We assume that investors place the same value on wealth which their heirs realize as on the wealth they recefve if they harvest an asset. Appendices explain the notation and contain the details of some of the calculations. 
I. The Basic Model

A. The Ordinary sector

A dollar invested in the ordinary sector yields a constant stream of gross returns $y$. We abstract from the entangling detail of the real world by assuming a simple proportional tax. Thus, after tax returns are $y\left(1-\tau_{0}\right)$ where $\tau_{0}$ is the tax rate in the ordinary sector. The tax rate $\tau_{0}$ cannot be identified with any single parameter of the tax code such as the corporate profits tax. Auerbach (1979) and others have analyzed the complex ways in which the provisions of the tax law combine to produce $\tau_{0}$. If the stream of returns is not constant, $\tau_{0}$ is even more complicated.

1. The After Tax Rate of Return.

We define the after tax rate of return $r$ as the solution to

$$
1=\int_{0}^{\infty} y\left(1-\tau_{0}\right) e^{-r s} d s
$$

Thus, $y=r /\left(1-\tau_{0}\right)$. Since $r$ is the rate of return available in the ordinary sector in a competitive economy it is the rate which all investors will use to discount all future benefits. In a complete model $r$ will be determined by the interaction between tastes (particularly time preference), technology and endowments. In this paper we analyze the effects of changes in parameters, particularly tax parameters, which do not affect the ordinary sector. Since these parameters shifts leave $r$ unchanged, we can use $r$ to assay the effects of such changes on economic efficiency. 
2. Gross Returns and the Value of Investment.

If goverment revenues are used efficiently -- or if, equivalently, proceeds of taxation are returned to taxpayers - a dollar of tax. revenue collected at time $t$ is worth $e^{-r t}$. Thus the taxes collected from an investment project yielding a stream of returns $y()$ have a present discounted value of $\int_{0}^{\infty} y(s) \tau_{0} e^{-r s} d s$ which, because of $(1)$, is equal to $\tau_{0} /\left(1-\tau_{0}\right)$. Thus a dollar invested in the ordinary sector produces a stream of returns which is worth $1+\tau_{0} /\left(1-\tau_{0}\right)=\left(1-\tau_{0}\right)^{-1}$ dollars when both private benefits and the value of tax benefits are considered. The fact that a dollar of investment produces more than a dollar's worth of benefits, can lead to complications. Anything that increases savings and Investment increases welfare. If proceeds of investment are reinvested they are worth more than if they are consumed. By positing mechanical rules for reinvesting proceeds of investment projects, we could derive alternative formulae for valuing dollars of investment. Our concern in this paper is with valuing investments in different sectors and it does not seem worthwhile to follow this line of analysis, at least in part because to follow It we would need to assume that the allocation of investment between sectors was also fixed pechanically. Another way of $=$ aking the same point is to say that we are assuming that the total anont of investment is fixed. Given this we examine the efficiency of the allocktion of resources to investment, both within and between sectors.

\section{B. Austrian Sectors}

In the economy there are 21 so Aus: Austrian investzents are point input, pint ouz:-it processes. An invesiment 
at an initial time $t_{0}$ produces an asset which has a value of $x\left(t-t_{0}\right)$ if the asset is harvested and used for consumption at time $t$.

\section{Wine and Trees.}

We consider two kinds of Austrian production processes. In the first, and simpler, an initial investment produces an asset which increases in value as it ages. We call the output of this process wine. The other Austrian output, a tree, is distinguished from wine by the fact that it uses a scarce resource, land, as it ages. When a tree is felled, another can be planted in its place. When wine is drunk, the bottle in which it has matured is discarded. We need terms to describe the time when an Austrian asset's maturation is terminated and it is consumed. For trees "cutting time" seems appropriate. For wine we shall call this time "selling time." This usage is justified in Proposition 3, below where it is shown that the capital gains tax discourages transfers of wine before it is consumed. Since the arguent of Proposition 3 can be adapted to trees, we shall also occasionally use selling time to refer to trees and wine together.

\section{Values and Rates of Return Without Taxes.}

Suppose that there are no taxes in the Austrian sector. In equilibrium assets invested in the Austrian sector must earn a rate of return equal to $r$. If they earn a rate of return greater than $r$, the value of resources used to produce wine will be bid up until the Iate of IEturn is 
just $r$. If $\mathrm{B}$ is the value or price of resources used to produce wine which has a value of $X(t)$ when sold or harvested after $t$ years,

$$
B=\max _{t} e^{-r t} X(t)
$$

We will deftne $\hat{t}$ as the solution to this maximization problem.

In equilibrium, scarce resources in the other Austrian sector (trees)

also earn the competitive rate of return, but since the scarce resource, land, is not used to produce trees but to provide a place for them to mature, the analysis is slightly different.

If trees can be planted at cost $P$, the present discounted value of a plot of land which can support one tree forever is, if trees are harvested at intervals of length $u$, and if the value of a tree of age $u$ is $v(u)$,

$$
\begin{aligned}
L(u) & =-P+(V(u)-P) e^{-r u}+(V(u)-P) e^{-2 r u}+\ldots \\
& =-P+(V(u)-P)\left(e^{r u}-1\right)^{-1} .
\end{aligned}
$$

The optimal cutting period $\hat{u}$ is chosen to maximize $L(u)$; if used in the Austrian sector this plot of land has a value of $L(\hat{u})$. If used in the ordinary sector it has an alternative value, say $L_{0}$. It is used in the sector in which it has the higher value.

C. Capital Gains Taxes, Realization.

In this section we analyze the Eîfects of capital gains taxes which are levied on a realization basis. In the next section we analyze the effects of capital gains taxes levied on an accrual basis. 
1. Wine.

Consider an investment in wine which if harvested and sold at time $t$, will yield $x(t)$. If the wine initially costs $B$, capital gains are $[X(t)-B]$. If capital gains are taxed when realized at rate $\tau$ net proceeds are

$$
(X(t)-B)(1-\tau)+B=X(t)(1-\tau)+\tau B
$$

The cutting time is chosen to maximize the present discounted value of these net proceeds. In equilibrium investments earn the competitive rate of return so that B satisfies.

$$
B=\operatorname{Max}_{t} e^{-r t}[X(t)(1-\tau)+\tau B]=e^{-r t^{\star}}\left[X\left(t^{\star}\right)(1-\tau)+\tau B\right]
$$

where the selling time t* maximizes the present discounted value of the investor's after tax profits. In interpreting (3) it should be kept in mind that $r, T$ and $X()$ are parameters while $B$ and $t \star$ are chosen to satisfy (3). If $I$ and $X()$ are held constant $B$ and $t *$ are functions of $T$. $B$ is the value of the investoent opportunity represented by $x()$. If the real cost of the resources used to produce $X()$ cost less than $B$ then these resources will be used to produce wine; competition will cause the value of these resources to rise to $B$. If they cost more than $B$, the wine which has the value stream $X()$ will not be projuced.

The present discounted velue of the total returns to an investment of E doIlars in wine is $y(t *) e^{-r t *}$. We can rewite (3) to see that

$$
X\left(t^{*}\right) e^{-r t *}=5\left(\frac{I-T e^{-I t *}}{I-I}\right) .
$$


Let a denote the present discounted value of the return to one dollar Invested in wine. Then

$$
\alpha=\left(1-\tau e^{-r t \star}\right) /(1-\tau)
$$

A dollar invested in the ordinary sector produces returns with a total discounted value of $\left(1-\tau_{0}\right)^{-1}$. The reason why these formulae differ is easy to understand. Considered solely in terms of costs and returns on investment wire is like an ordinary investment which requires an initial investment of $B$ and returns $X(t), t$ periods later when it is sold. 4 . If It were taxed as an ordinary investment, the tax base would be $x(t)$, $\operatorname{tax}$ revenues would be $T X(t)$ and the total return from a dollar's worth of investment would be $(1-\tau)^{-1}$. Since investments in wine are taxed as capital gains the tax base is not $X(t)$ but $X(t)-B$. We summarize this discussion in

Proposition 1: The present discounted value of total returns from a dollar invested in wine is less than the present discounted value of total returns from a collar invested in the ordinary sector if and only if

$$
\left(1-\tau e^{-r t \star}\right) /(1-\tau)<\left(1-\tau_{0}\right)^{-1}
$$

4 There is a slight, and inessential, technical difference. In order to use continuous time we assume that returns from ordinary investments are flows while returns from Austrian investments are stocks. 
If $\tau \leq \tau_{0}$, then returns to investments in the ordinary sector are greater than returns to investments in wine. If $\tau>\tau_{0}$, then returns to investments in wine may or may not be greater than returns to ordinary investments. Since different kinds of wines may have different selling times (different $\left.t^{*}\right)$ it is quite possible that some wine investments may have greater and some lesser total social returns than ordinary investments. In interpreting the condition $\tau \leq \tau_{0}$ it is well to keep in mind what a complicated parameter $\tau_{0}$ is.

The value of $B$ determines the allocation of resources to the wine sector. As B increases more resources are devoted to the production of wine. Whether or not this increases or decreases economic well-being depends on (4). In contrast, the parameter t* determines the efficiency with which resources in the wine sector are used. The value of all resources devoted to wine grows according to the function $x()$. Since the social discount rate is $r$, the wine should be allowed to mature until $\hat{t}$ where $\hat{t} \operatorname{maximizes.} e^{-r t} X(t)$. Assuming, as we shall, that $X^{\prime}(t) / X(t)$ is a decreasing function, $\hat{t}$ is the unique solution to

$$
X^{\prime}(\hat{t}) / X(\hat{t})=r
$$

However, the selling time for wine, $t *$, is chosen to waximize private return not social return; $t *$ satisfies not (5) but (3), thus $t *$ zust satisfy

$$
X^{\prime}\left(t^{*}\right) / X\left(t^{*}\right)=r\left(1+\frac{T}{1-\tau} \frac{B}{X\left(t^{*}\right)}\right)
$$


Proposition 2: $t \star<\hat{t}$.

In interpreting this proposition it should be remembered that while each wine investment mav have a different soclally optimal selling time $\hat{t}$ and a different privately optimal selling time $t *$ for all such investments the privately optinal time is too short. Were it to increase, the resources allocated to the wine sector would be used more efficiently and the present discounted value of the output of the wine sector would increase. Like proposition 1, proposition 2 is a consequence of the form of capital gains taxation. If wine were taxed as ordinary income the after tax return would be $X(t)(1-\tau)$ and $t^{*}$. would be chosen to maximize $(1-\tau) X(t) e^{-r t}$ so $t *$ would equal $\hat{t}$.

A high basis increases the value of an asset subject to capital gains taxation. It is conceivable that this effect could be strong enough to encourage turnover of assets like wine. Working against this is the fact that capital gains taxes are also turnover taxes and thus they inhibit transactions. We show in Proposition 3 that this latter effect dominates.

Proposition 3. No wine is sold before it is consumed.

Proof: Suppose first that the basis is 0 . In this case the wine will be consumed at the same time as it would be were there no tax. The value of holding the wine to maturity is

$$
W^{\tau}(0)=\operatorname{Max}_{t} e^{-r t} X(t)(1-\tau)=(1-\tau) \operatorname{Max}_{t} e^{-r t} X(t)=(1-\tau) W^{0}
$$

If the pezson sells the asset imediately for a price $S$ he will net, after taxes, only $(1-\tau) S$. Thus he will be better off selling only if $S(1-\tau) \geq$ $(1-i) W^{0}$ or if $S \geq H^{0}$. However, it is easy to see that no person facing the capital gajas tex will pay pore than $w^{0}$ to buy the asset. A prospective buyer is wiline te fey orly $s$ where $s$ is a solution to 


$$
S=\operatorname{Max}_{t}\left[[\dot{X}(t)(1-\tau)+\tau S] e^{-r t}=e^{-r \tau^{\star}} X\left(\tau^{\star}\right)(I-\tau)+\tau S e^{-r t \star}\right.
$$

Thus

$$
S\left[1-\tau e^{-r t \star}\right]=e^{-r t \star} X(t *)(1-\tau)
$$

or

$$
S=e^{-r t^{*}} X\left(t^{*}\right) \frac{1-\tau}{I-\tau e^{-r t^{*}}}<e^{-r t^{*}} X\left(t^{*}\right) \leq \underset{t}{\operatorname{Max}} e^{-r t} X(t)
$$

If the basis is $B$, then $W^{\top}(B)>W^{\top}(0)$ so a sale would have to realize even more than $w^{0}$ for it to be preferable to holding the asset until maturity. This argument considers a sale only at time $t=0$, but it obviously generalizes to sales at other times. This proof depends heavily on our assumption that all investors face the same capital gains tax.

The capital gains tax affects both the allocation of wine between sectors, through $B$, and the efficiency with which resources in the wine sector are used, through $t^{*}$. The signs of these effects are determinate.

Proposition 4: Both $B$ and $t *$ are decreasing functions of $T$.

Proof: 1) Let $G(B, \tau, t)=e^{-I t}(X(t)(1-\tau)+\tau B)$;

$$
\psi(B, \tau)=\underset{t}{\operatorname{argmax}} G(B, \tau, t) \text { and } H(B, \tau)=G(B, \tau, \psi(B, \tau))-B \text {. }
$$

In equilibriun $\mathrm{B}(\mathrm{B}, \tau)=0$ so $\frac{\mathrm{dB}}{\mathrm{d} \tau}=-\frac{\mathrm{H}_{2}}{\mathrm{H}_{1}}$. But $\mathrm{H}_{1}=\mathrm{G}_{1}+\mathrm{G}_{3} \frac{\partial \psi}{\partial \mathrm{B}}-1=\mathrm{G}_{1}-1=$ $\tau \exp (-I(B, \tau))-I<0$. The second step follows from the envelope theorem, $G_{3}(B, \tau, \quad(B, \tau))=0 . \quad$ similarly 


$$
\mathrm{H}_{2}=G_{2}+G_{3} \partial \psi / \partial \tau=G_{2}=(\exp (-I \psi(B, \tau))(B-X(\psi(B, \tau)) .
$$

Thus, letting $t^{*}=\psi(B, \tau)$,

(7) $\quad \frac{d B}{d \tau}=\frac{e^{-r t *(B-X(t *))}}{1-\tau e^{-r t^{\star}}}<0$.

2) To calculate $d t * / d \tau$ we note that $B$ is a function of $\tau$ and that $t *$ maximizes $F(t, \tau)=e^{-r t}(X(t)(1-\tau)+\tau B(\tau))$ so that $t *$ must satfsfy

$$
0=F_{1}(t *, \tau)=-r F+e^{-r t *} X^{\prime}\left(t^{*}\right)(1-\tau)
$$

Thus, $\frac{d t^{*}}{d \tau}=-\frac{F_{12}}{F_{11}}$ and, since $F_{11}<0$ by the second order conditions for maximizing $F$ with respect to $t$, it follows that sign $d t * / d \tau=\operatorname{sign} F_{12}$. But using (3), (7) and (8) we have that

$$
\begin{aligned}
& F_{12}=-r F_{2}-e^{-r t \star} X^{\prime}(t *) \\
& =-r e^{-r t^{*}}(B-X+\tau d B / d \tau)-e^{-r t^{*}} x^{\prime} \\
& =e^{-r t^{*}} r\left[\left(X-B+\frac{\tau(X-B)}{e^{r t^{*}}-\tau}\right]-\frac{r F}{1-\tau}\right. \\
& =e^{-r t *} r\left[\frac{(X-B) e^{I t *}}{e^{I t *}-\tau}\right]-\frac{r B}{1-\tau} \\
& =r\left[\frac{X-B}{e^{I t *}-\tau}-\frac{B}{1-\tau}\right] \\
& =r\left[\frac{X}{e^{x t *}-\tau}-B\left[\frac{1}{e^{I t *}-\tau}+\frac{1}{1-\tau}\right]\right] \\
& =\frac{-I B}{e^{I t^{\star}}-\tau}<0 .
\end{aligned}
$$


Proposition 4 indicates that the effects of increasing the capital gains tax on economic efficiency are complex. If inequality (4) holds -- as it will whenever $\tau \leq \tau_{0}--$ then increasing $T$ improves efficiency by diverting funds from the wine sector into the ordinary sector $(d B / d \tau<0)$; the efficiency of the resources used in the wine sector will decrease as increasing taxes causes wine to be harvested sooner than it should be $(d t * / d \tau<0)$.

2. Trees.

The analysis for trees is much simpler. As Lippman and McCall (1980) have observed, the optimal cutting time $u^{*}$ is independent of the rate at which a proportional capital gains tax is levied. We model the effect of the capital gains tax by assuming the owner of a tree pays a tax on the increase in the tree's value from $P$, its initial cost, to $V(u)$. Thus, assuming he plants another tree, his after tax cash flow at time $u$ is $(V(u)-P)(1-\tau)+P-P=(V(u)-P)(1-\tau)$. Thus (2) is changed to

$$
\begin{aligned}
L(u)=-P & +e^{-I u}((V(u)-P)(1-\tau)+P-P) \\
& +e^{-I 2 u}(V(u)-P)(1-\tau)+\ldots \\
& =-P+\frac{V(u)-P}{e^{I u}-1}(1-\tau)
\end{aligned}
$$

so that $u *$ is chosen to maximize $\frac{V(u)-P}{e^{r u}-1}$ independent of $\tau$.

It is worth noting that this does not hold for all tree investments; It is a consequence of the assumption that investment opportunities in the tree sector are stationary. If a plot of land will support a sequence of 
trees each associated. with a planting cost $P_{i}$ and a potential value stream $v_{1}$, the sequence of cutting times $\{\underset{\sim}{u}\}=\left(u_{1}, u_{2} \ldots\right)$ will be chosen to maximize

$$
\begin{aligned}
\underline{L}\{\underline{u}\}=-P_{1} & +e^{-r u_{1}\left[\left(v_{1}(u)-P_{1}\right)(1-\tau)+\left(P_{1}-P_{2}\right)\right]} \\
& +e^{-r\left(u_{1}+u_{2}\right)}\left[\left(v_{2}(u)-P_{2}\right)(1-\tau)+\left(P_{2}-P_{3}\right)\right] \\
& =-P_{1}+\sum_{i=1}^{\infty}\left(\exp -r\left(\sum_{k=1}^{1} u_{k}\right)\right)\left[\left(v_{1}\left(u_{i}\right)-P_{i}\right)(1-\tau)\right. \\
& \left.+\left(P_{i}-P_{i+1}\right)\right] .
\end{aligned}
$$

The optimal sequence $\{\underline{u} *\}$ will be independent of $\tau$ if and -- for all practical purposes -- only if $P_{i}=P$ for all $i$. If the sequence of planting costs is not stationary $\tau$ will affect the efficiency of resource use in the tree sector.

Proposition 6: If planting costs are constant, $\left\{u^{\star}\right\}=\{\hat{u}\}$.

The analysis of total return in the tree sector has elements of the analysis in the ordinary sector and of the analysis in the wine sector. To deal with the non-stationary case we analyze total returns from one cycle of investment. Total investment is land withdrawn from production for u periods and the planting cost $P$. Total after tax returns are $(V(u)-P)(1-T)+P$ Thus, we have, in equilibrium.

$$
L\left(1-e^{-I u}\right)+P=(V(u)-P)(1-\tau) e^{-r u}+P e^{-r u}
$$

Solving for total return we obtain

$$
V(u) e^{-r u}=\frac{I(u)\left(1-e^{-r u}\right)+P}{1-\tau}-\frac{\tau P e^{-r u}}{1-\tau}
$$

A dollar of investment thus brings total returns equal to

$$
\frac{1}{1-\tau}-\frac{\tau}{1-\tau} e^{-\tau u} \frac{P}{L\left(1-e^{-\Gamma u}\right)+P} .
$$


Proposition 7. The present discounted value of total returns from a dollar Invested in the tree sector is $\frac{1-\tau e^{-\tau u_{\delta}}}{1-\tau}$ where $u$ is the cutting time of the tree and $\delta$ is the ratio of planting costs to total investment costs.

\section{Accrual Taxation}

It is sometimes asserted that many of the distortions and inefficiencies which the capital gains tax causes are due to the fact that capital gains are taxed on a realization basis; if taxation were on an accrual basis these distortions would disappear. We examine this claim by analyzing the effect of accrual taxation on the efficiency of allocation of resources between and within investment sectors. Our model does not support the proposition that accrual taxation is to be preferred on efficiency grounds. Accrual taxation introduces distortions different from, and in some cases greater than, the distortions caused by realization taxation. While some parameter values may favor accrual taxation, one cannot make a strong a priori case for it -- at least using the model of this paper. If anything the evidence seems to run the other way. We observed above that in the stationary case taxation on a realization basis does not affect the cutting time of trees. We will see in Proposition 10 below that the cutting time of trees is a decreasing function of the rate of accrual taxation.

1. Hine

We begin our analysis by noting that the effect of accrual taxation on wine is to force investors to behave as if their discount rate were $I /(I-T)$. rather than $r$; furthermore, trees taxed on an accrual bas is w111 be cut Con- sooner then when taxed on a realization basis at the same rate. 


\section{Proposition 8.}

If taxed on an accrual basis at rate $T$, wine with a growth path of $X()$ will be harvested at $t$ ime $t_{a}$ where $t_{a}$ satisfies $X^{\prime}\left(t_{a}\right) / X\left(t_{a}\right)=r /(I-\tau)$. The. present discounted value of such wine is $X\left(t_{a}\right) \exp -(r / 1-\tau) t_{a}$. Furthermore $\frac{d t_{a}}{d \tau}<0$ and $t_{a}<t^{*}$ where $t^{*}$ is the harvesting time when wine is taxed on $a$ realization basis at rate $\tau$.

\section{Proof:}

1) The key to the proof is our assumption that taxes are levied on increases in the market value of the wine. That is, if $W(t)$ is the value of the wine at time $t$, increases in $W(t)$ must satisfy

$$
W(t)=e^{-I \Delta t}[W(t+\Delta t)(I-\tau)+\pi(t)]
$$

This formula assumes that the investor bought the tree for $W(t)$ in period $t$ and sold it for $W(t+\Delta t)$ in period $t+\Delta t$ realizing an after tax return of $(1-\tau) W(t+\Delta t)+T W(t)$; if $\Delta t$ is sufficiently small there is no difference between taxation on an accrual basis and taxation on a realization basis. Using Taylor series to evaluate the right hand side of (11) and discarding all terms of order $(\Delta t)^{2}$ or greater we see that $W(t) r \Delta t=W^{\prime}(t)(1-\tau) \Delta T$ or,

$$
\frac{W^{\prime}}{W}=\frac{I}{1-\tau}
$$

This first order differential equation describes the evolution of $W(t)$, the value of the tree. A boundary condition is that $h\left(t_{a}\right)=x\left(t_{a}\right)$ if the tree is cut down at time $t_{a}$. Thus, the present discounted value of a tree taxed on an accrual basis at rate t which will be cut donn at $t$ is just $x\left(t_{a}\right) e^{-(r /(1-\tau)) t} a$. Clearly $t_{a}$ should be chosen $t c$ axirize this value. 
2) That $d t_{a} / d \tau<0$ follows 1mediately from the fact that $\frac{d(I /(I-T))}{d \tau}>0$.

3) Let $t *$ be the cutting time when taxed on a realization basis with

basis $B$. Then

$$
\begin{aligned}
\frac{X^{\prime}\left(t^{*}\right)}{X\left(t^{*}\right)} & =r\left[1+\frac{\tau}{1-\tau} \frac{B}{X\left(t^{*}\right)}\right]<r\left[1+\frac{\tau}{1-\tau} \frac{X\left(t^{*}\right)}{X\left(t^{*}\right)}\right]= \\
& =r\left(1+\frac{\tau}{1-\tau}\right)=r /(1-\tau)=\frac{X^{\prime}\left(t_{a}\right)}{X\left(t_{a}\right)}
\end{aligned}
$$

Since $X^{\prime}(t) / X(t)$ is a decreasing function of $t, t_{a}<t^{\star}$.

We thus see that accrual taxation leads to a more inefficient use of resources within the wine sector than taxation on a realization basis at the same rate. We note that if $\tau=\tau_{0}$, the rate which investors use to discount returns in the wine sector is equal to the gross or pretax rate of return in the ordinary section. If $\tau=\tau_{0}, y=\frac{r}{1-\tau}$. Define the gross rate of return $R$ as the solution to

$$
I=y \int_{0}^{\infty} e^{-R s} d s=\frac{y}{R}
$$

so that $\mathrm{R}=\mathrm{y}=\mathrm{r} /(1-\tau)$, the discount rate used by private investors facing accrual taxation at rate $\tau$ in the wine sector. This observation is of somewhat limited interest as $r$, not $R$, is the social rate of discount; it is not efficient to decide when to harvest wine by using the rate $R$ as a discount rate.

Accrual taxation does not lead to the correct allocation of resources between the wine and the ordinary sector even when $\tau=\tau_{0}$. 


\section{Proposition 9}

The present discounted value of a dollar of resources invested to wine is $\exp [\mathrm{rt}$ a $\tau /(1-\tau)]$.

\section{Proof:}

Consider one dollar invested in wine which goes to produce wine har-

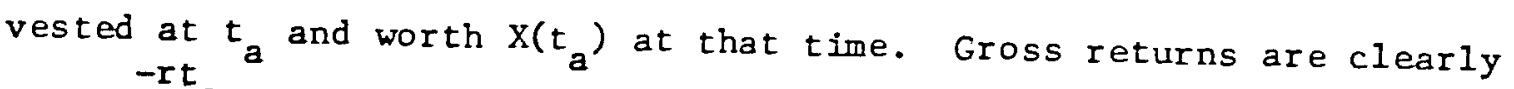
$x\left(t_{a}\right) e^{-r t a}$. However, In equilibrium the present discounted value of after tax returns is equal to one dollar so $x\left(t_{a}\right)=e^{(r /(1-\tau)) t_{a}}$. Substituting, we find gross returns from one dollar are

$$
\exp \left[t_{a}(r /(1-\tau)-r)\right]=\exp \left[r t_{a} \tau /(1-\tau)\right]
$$

Since gross returns are the sum of private returns and the present discounted value of taxes paid this latter amount must be $e^{r t_{a} \tau / 1-\tau}-1$ per dollar invested in wine.

We note that whether the total return from investments in wine are greater or less than returns in the ordinary sector depends on whether (12) $\quad(1-\tau) e^{\text {rt }} a^{(\tau /(1-\tau))} \gtrless 1$

Because $t_{a}$ is a function of $\tau$, the expression on the left hand side of (12) is quite complicated to analyze. We give examples in Appendix II-A which show that this expression can be greater or less than 1, that it can be increasing or decreasing in $\tau$, and that its limit as $\tau$ approaches $I$ can be either 0 or $\infty$. 


\section{Trees}

The effects of accrual taxation on trees are also straightforward. The analysis of Proposition 8 applies. A tree cut down after u years of growth yields an after-tax return with a present discounted value of $\mathrm{V}(\mathrm{u}) \mathrm{e}^{-\mathrm{ur} /(1-\tau)}$. If planting a tree costs $\mathrm{P}$, a plot of land on which trees are planted yields returns which are equivalent to the payment of $V(u) e^{-u r /(1-\tau)}-P$ ut times $0, u, 2 u, \ldots$ Thus the value of land is

$$
L(u)=\frac{V(u) e^{-u r /(1-\tau)}-P}{1-e^{-r u}}
$$

The optimal cutting time, $u_{a}$, is chosen to maximize the right hand side of (13). It is immediately clear from (13) that $u_{a}$ is not, as in the realization case, independent of the rate of capital gains taxation. We show in Proposition 10 that $\frac{d u_{a}}{d t}<0$. The optimal cutting time is, as analyzed above, $\hat{u}$. If the rate of capital gains taxation is zero then $u_{a}=\hat{u}$. Thus accrual taxation leads to trees being cut down too soon.

\section{Proposition 10.}

The optimal cutting time for trees which are taxed on an accrial basis is a decreasing function of the tax rate.

Proof:

By definition

$$
u_{a}=\underset{u}{\operatorname{argmax}} \frac{V(u) \exp (-r u /(1-\tau))-P}{1-e^{-r u}}
$$


Assuming an interior solution, the first order conditions imply

$$
\begin{aligned}
P \leq V\left(u_{a}\right) & \exp \left(-r u_{a} /(1-\tau)\right) \\
\varphi\left(u_{a}, \tau\right)= & {\left[\left[V^{\prime}\left(u_{a}\right) \exp \left(-r u_{a} /(1-\tau)\right)-V\left(u_{a}\right)\left(\frac{r}{1-\tau}\right) \exp \left(-r u_{a} /(I-\tau)\right)\right]\right.} \\
& \left.\cdot\left[1-e^{-r u_{a}}\right]-\left[-P+V\left(u_{a}\right) \exp \left(-r u_{a} /(1-\tau)\right)\right] r e^{-r u_{a}}\right\} \\
& \div\left[1-e^{-r u_{a}}\right]^{2}=0 .
\end{aligned}
$$

Thus

$$
\frac{d u_{a}}{d \tau}=-\frac{\partial \varphi / \partial \tau}{\partial \varphi / \partial u_{a}}
$$

and, since $\partial \varphi / \partial u_{a}<0$ by second order conditions,

$$
\operatorname{sign} \frac{d u_{a}}{d \tau}=\operatorname{sign} \frac{\partial \varphi}{\partial \tau}=\operatorname{sign}\left\{\left(e^{-r u_{a}}-1\right)\left(\frac{V^{\prime}\left(u_{a}\right) u_{a}}{V\left(u_{a}\right)}+1\right)+\frac{r u_{a}}{1-\tau}\left(1-\tau e^{-r u_{a}}\right)\right\}
$$

Rearranging the first order condition (16), we find that

$$
\begin{aligned}
\left(\frac{V^{\prime}\left(u_{a}\right) u_{a}}{V\left(u_{a}\right)}+1\right)\left(e^{-r u_{a}}-1\right) & +\frac{r u_{a}}{1-\tau}\left(1-\tau e^{-r u_{a}}\right)=\frac{P u_{a}}{V\left(u_{a}\right)} r e^{-r u_{a}} \exp \left(\frac{r u_{a}}{(1-\tau)}\right) \\
& +e^{-r u_{a}}-1 .
\end{aligned}
$$

Thus,

$$
\operatorname{sign} \frac{d u_{a}}{d \tau}=\operatorname{sign}\left\{\frac{u_{a}}{v\left(u_{a}\right)} \operatorname{Pr} e^{-r u_{a}} \exp \left(\frac{r u_{a}}{(I-\tau)}\right)+e^{-r u_{a}}-1\right\}
$$


From $(15)$ we know that $P \leq V\left(u_{a}\right) \exp \left(-r u_{a} /(1-\tau)\right)$, which implies (17) $\frac{u_{a}}{v\left(u_{a}\right)} \operatorname{Pr} e^{-r u_{a}} \exp \left(r u_{a} /(1-\tau)\right)+e^{-r u_{a}}-1 \leq\left(u_{a} r+1\right) e^{-r u_{a}}-1$

The right hand side of $(17)$ attains a maximum over $u_{a} r \geq 0$ when $u_{a} r=0$. At this point $\left(u_{a} r+1\right) e^{-r u} a+1=0$. Thus, $\frac{d u_{a}}{d \tau} \leq 0$.

When we analyze the gross returns to investment in trees with accrual taxation, we get a result which is similar to Proposition 9.

\section{Proposttion 11:}

If capttal gains are taxed on an accrual basis at rate $\tau$, the gross return to one dollar invested in trees is $\exp \left(r u_{a} \tau /(1-\tau)\right)$.

Proof: To see this, consider again an investment in a single tree. Land worth $L\left(u_{a}\right)$ is used for a period of $u_{a}$ and resources worth $P$ are used to plant the tree. These costs bring a private return of $v\left(u_{a}\right) e^{-\left(r /(1-\tau) u_{a}\right.}$. Total returns from these costs are $V\left(u_{a}\right) e^{-r u a}$. Thus the ratio of total returns to private returns, which is also in equilibrium the gross return to an investment of one dollar, is $\exp \left(r u_{a} \tau /(1-\tau)\right)$.

The discussion following Proposition 9 applies here. Whether the rate of return to trees taxed on an accrual basis is greater or less than the rate of return in the ordinary sector depends on the nature of the function 
$V()$. It is well known that as $P$ increases to the point where $L\left(u_{a}\right)=0$, $u_{a}$ converges to $t_{a}$; that is, $u_{a}$ satisfies $v^{\prime}\left(u_{a}\right) / v\left(u_{a}\right)=r /(1-\tau)$. Thus, the examples of Appendix II.A demonstrate that $(1-\tau) \exp \left(r u_{a} \tau /(1-\tau)\right.$ can be increasing or decreasing in $\tau$ and that $\lim _{\tau \rightarrow 1}(1-\tau) \exp \left(\mathrm{ru}_{\mathrm{a}} \tau /(1-\tau)\right)$ can be either 0 or $\infty$. 


\section{Inflation}

\section{A. The Ordinary Sector}

We model inflation in the ordinary sector by assuming that a dollar invested yields a stream of gross returns $y(s) e^{n s}$. The after tax rate of return, $\nu$, is now the solution to

(18) $\quad 1=\int_{0}^{\infty} y(s) e^{n s}\left(1-\tau_{0}\right) e^{-v s} d s$.

If $r$ is the after tax rate of return in the ordinary sector without inflation, it is straightforward to show that $v=r+\eta ; r+\eta$ is the rate which investors will use to discount all future benefits.

If goverment revenues are used efficiently a dollar of tax revenue collected at time $s$ has a present discounted value equal to $e^{-(I+n) s}$. Thus, the present discounted value of taxes collected is again $\frac{\tau_{0}}{1-\tau_{0}}$. As in the case with no inflation, a dollar invested in the ordinary sector produces a total stream of returns with present discounted value equal to $\left(1-\tau_{0}\right)^{-1}$.

\section{B. The Austrian Sectors}

Our analysis of the effects of inflation on the Austrian sectors focuses on the two distortions examined earlier. Table 1 sumarizes the effects of inflation on selling time and value of gross return for wine and trees under both accrual taxation and taxation on a realization basis. The details of the derivation of the entries in Table 1 are tedious and are giver in Appendix II. Fere we sumarize and explain the results. 


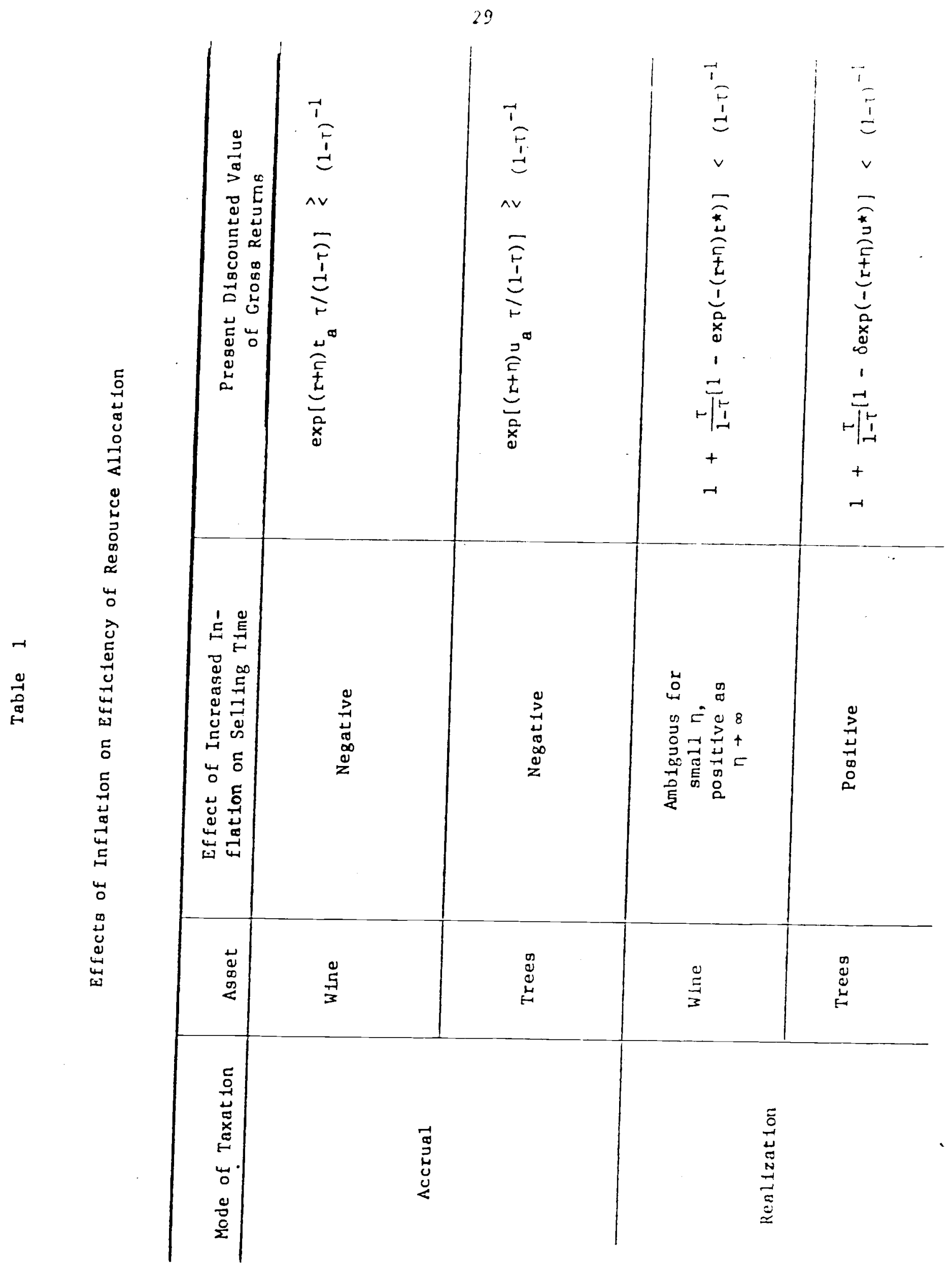


Under accrual taxation, the analysis of the effects of inflation is straightforward, but the effects themselves defy simple summary. About all that can be said is that inflation complicates -- sometimes exacerbating and sometimes alleviating -- the distortions induced by taxation. If the inflation rate is $\eta$ and the tax rate is $\tau$, wine taxed on an accrual basis is exactly the same as wine which is untaxed but discounted at a rate $\frac{r+n \tau}{1-\tau}$. From (18) inflation can be modeled by assuming that the discount rate rises to $r+n$ while the nominal value of wine sold at time $t$ equals $x(t) e^{n t}$. Thus, wine harvested at time $t$ has a present discounted after tax value of

$$
x(t) e^{n t} \exp \left[-\frac{(r+n)}{(1-\tau)} t\right]=x(t) \exp \left[-\frac{(r+n \tau)}{(1-\tau)} t\right]
$$

The selling time of wine, $t_{a}$, maximizes the expression above. This gives us the first order condition

$$
\frac{x^{\prime}\left(t_{a}\right)}{X\left(t_{a}\right)}=\frac{r+\pi \tau}{1-\tau}
$$

The right hand side of this equation is increasing in $\eta$. Thus, $t_{a}$ is decreasing in $N$.

The calculation of the present discounted value of gross returns under inflation is similar to that of Proposition 9, only now the discount rate $r+\eta$ is substituted for $r$; the gross rate of return is

$$
\exp \left[(r+\eta) t_{a} \tau /(1-\tau)\right]
$$

which, as examples in Appendix II.B show, can be increasing or decreasing in $\eta$. Trees are again more complicated than wine but the effects of inflation are cualitatively the same. The optimal cutting time $u_{a}$ satisfies 


$$
u_{a}=\underset{u}{\operatorname{argmax}} \frac{v(u) \exp \left[-\frac{(r+\tau \eta)}{(1-\tau)} u\right]-P}{1-e^{-r u}}
$$

This is similar to the expression in the case without inflation, (14), with $\frac{r+n \tau}{1-\tau}$ substituted for $\frac{r}{1-\tau}$.

The proof that the optimal cutting time $u_{a}$ is decreasing in $\eta$ is left to Appendix II.C. Since $V\left(u_{a}\right) \exp [-(r+n \tau) /(1-\tau)] u_{a}$ and not $V\left(u_{a}\right) \exp [-r /(1-\tau)]\left(u_{a}\right)$ is the present discounted after tax rate of return to investing in trees, the argument used to establish Proposition 11 also establishes that the gross rale of return to investment in trees is equal to $\exp \left[(r+\eta) u_{a} \tau /(1-\tau)\right]$. Again, since $u_{a}$ approaches $t_{a}$ when $L\left(u_{a}\right) \rightarrow 0$, the examples in Appendix II.B show that this expression can either increase or decrease as $n$ increases.

The analysis of inflation with taxation at realization is somewhat less straightforward, although the results themselves fit into a simple pattern. Consider first wine. The present discounted value of the after tax return from wine with basis $B$, sold at date $t$ is

$$
\begin{aligned}
W(t, \tau, \eta) & =e^{-(r+\eta) t}\left[X(t) e^{\eta t}(1-\tau)+\tau B\right] \\
& =e^{-r t} X(t)(1-\tau)+e^{-(\eta+r) t} \tau B
\end{aligned}
$$

The owner of wine with base $B$ will choose a harvesting time $t *(\tau, \eta)$ which solves

$$
\underset{t}{M a x} W(t, T, \pi)
$$

The irst order condition which t* wust satisfy is

$$
\begin{aligned}
& \psi\left(t^{\star}, \tau, \eta\right)=e^{-\left(\Gamma^{+} \Gamma\right) t^{*}}\left\{-r X\left(t^{\star}\right) e^{n t^{\star}}(1-\tau)-\right. \\
& \left.-(i+r) \tau \dot{B}+x^{\prime}\left(t^{*}\right) e^{n t *}(1-\tau)\right\}=0
\end{aligned}
$$


Let $W^{*}(\tau, n)=W(t *(\tau, n), \tau, n)$. In equilibrium investments earn a competitive rate of return so that

$$
B=B(\tau, n)=W^{*}\left(\tau, \eta_{i}\right)=\operatorname{Max}_{t} e^{-(r+n) t}\left\{x(t) e^{\eta t}(1-\tau)+\tau B(\tau, n)\right\} .
$$

Rearranging, we find that

$$
B(\tau, n)=\frac{X\left(t^{\star}(\tau, n)\right)(1-\tau)}{\left[e^{r t^{\star}}-\tau e^{-\eta t^{\star}}\right]}
$$

Applying the implicit function theorem to (21) we find that

$$
\operatorname{sign} \frac{d t^{*}}{d \eta}=\operatorname{sign}\left[(n+r) t *-1+\tau e^{-(n+r) t *}\right]
$$

At low rates of inflation increases in $n$ can increase or decrease selling time, depending on the evolution of $\mathrm{x}(\cdot)$. In Appendix II.D we provide examples where $\left.\frac{d t^{\star}}{d n}\right|_{n=0}$ is greater than, less than, and equal to zero. As $\eta$ approaches $\infty$ the problem the owner of wine faces converges to the problem he would face if his basis were zero and there were no inflation. That 1s,

$$
W(t, \tau, \infty)=e^{-r t} Y(t)(1-\tau)
$$

Thus, since $t *<\hat{t}$, for sufficiently large $n, \frac{d t^{*}}{d n}>0$, and asymptotically, increases in the rate of inflation correct the distortion in selling time which the capital gains tax causes. This asymptotic behavior is further illustrated by the gross returns on investaent in wine. An investrent of one dollar in wine $\because \dot{i}$ ids an after tay reture $\because$ ith a present discounted value of 


$$
e^{-(r+\eta) t *}\left[x(t *) e^{n t *}(1-\tau)+\tau\right]
$$

if wine is sold at $t^{\star}$. The present discounted value of gross benefits generated by this dollar is $X(t *) e^{-r t *}$. Setting (25) equal to one and rearranging we find

$$
X(t *) e^{-r t^{*}}=1+\frac{\tau}{1-\tau}\left[1-e^{-(r+\eta) t^{*}}\right]
$$

Although this is less than $(1-\tau)^{-1}$, as $\eta$ approaches $\infty$ (26) converges to $(1-\tau)^{-1}$. Thus, for large $\eta$ increases in $\eta$ decrease the distortions of the capital gains tax.

A similar argument shows that inflation increases the present discounted value of gross returns to investments in trees taxed on a realization basis. If $\tau=\tau_{0}$, inflation reduces the distortion which the capital gains tax induces.

In contrast to the case of accrual taxation, these results fit into a simple pattern. Inflation, at least inflation at a rapid rate, reduces the distortions which a tax on realized capital gains induces. There is a straightforward explanation. The distortions which this tax induces stem from the exclusion of the base value of the asset from the tax base. Inflation reduces the value and the effect of this exclusion.

One entry in Table 1 does not fit this neat pattern. With no inflation trees taxed at realization are cut down at the socially optimal time. As 
Inflation increases, the cutting time of trees increases; inflation induces Inefficlency. The proof of this fact is tedlous and given in the appendix. However, there is a simple intuitive explanation. Inflation and taxation interact to make $1 \mathrm{t}$ appear to the investor that planting costs have increased. The investor chooses u to maximize

$$
\begin{aligned}
& \sum_{i=1}^{\infty} e^{-(r+n) u i}\left[V(u) e^{\eta u 1}(1-\tau)+\tau P e^{\eta u(i-1)}-P e^{\eta u i}\right] \\
& \quad=\sum_{i=1}^{\infty} e^{-r u 1}\left[V(u)(1-\tau)+\tau P e^{-\eta u}-P\right] .
\end{aligned}
$$

While in any period he must pay planting costs of $P$, when he pays taxes he can only exclude $\mathrm{Pe}^{-\eta \mathrm{n}}$ from his tax base. Effective planting costs have increased. The natural response is to use less planting by increasing the time between plantings. 


\section{Death and Taxes}

Death complicates. Until 1976, in the United States, when the holder of an asset died, the estate paid no capital gains tax; if the investor's heirs sold the asset in the future the basis value of the asset used to compute capital gains tax liability was its value on the date of the investor's death. From the point of view of the estate, death was equivalent to a sale on the date of death which escaped capital gains taxation. Although death may not have had much else to recommend it, it was a dandy way to avoid taxes. This system was changed in 1976, and the U.S. began to move toward a system like that analyzed in Part I in which the heir's basis would be the basis of the original purchaser of the asset. In 1980, this movement stopped; and the U.S. has reverted to the pre-1976 system.

In this part of the paper we analyze the effect of the capital gains tax on the selling time and value of Austrian assets when death alters the way in which capital gains are taxed. Special treatment of capital gains at death alters, and in some cases reverses, our conclusions about the effect of the capital gains taxes on selling time.

Let $F(t)$ be the probability that the owner of wine lives until at least period $t$. Then $F(0)=1, F(\infty)=0$ and $F(t)$ is decreasing. For simplicity we assume $F(t)$ is differentiable and let $f(t)=F^{\prime}(t)$. If the probability of death is constant then $F(t)=e^{-\gamma t}$ and $f(t)=-\gamma e^{-\gamma t}$. Let $\tau_{d}$ be the rate of capital gairs taxation at death. We consider two values of $\tau_{d}, \tau_{\dot{z}} \equiv 0$ corresponds to the present U.S. system - which is known as autoatic step up in basis or step up for short. Linder step up, capital Eains taxes are avoided at death. 
Another possible treatment of capital gains at death is what is known as constructive realization. Under this system the estate is presumed to sell the asset at death and to pay tax at the ordinary capital gains rate on the gains which the sale realizes. Under constructive realization

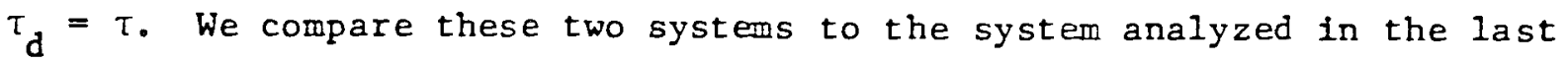
part which is referred to as a carryover system.

If an investor plans to sell an asset at $t$, the expected present discounted value of the after tax proceeds is

$$
\left.J(t)=e^{-r t} F(t)(X(t)(1-\tau)+\tau B)-\int_{0}^{t} e^{-r s}\left(X(s)\left(1-\tau_{d}\right)+\tau_{d} B\right)\right) f(s) d s .
$$

The first term in (27) represents the discounted after tax value he will receive if he lives until $t$. The second term is the discounted after tax value which his estate will receive. This formula is not quite correct for two reasons. First, the pretax value the estate realizes will in general be more than $x(t)$ since the value of the asset will exceed $x(t)$. Determining exactly what this value is seems very difficult. Secondly, in contrast to the analysis of section I above, B here is an arbitrary parameter. Although in principle B should satisfy a zero profit condition, it is hard to write down this condition for this model because investors'mortality functions will influence their profits. It is hard to figure out what should be the "market" mortality function. We think neither of these simplifications will affect our analysis.

The planned selling time $t^{\star}$ is chosen to maximize $J(t) ; t^{*}$ satisfies

(28) $\frac{X^{\prime}\left(t^{\star}\right)}{X\left(t^{\star}\right)}=I\left[1+\frac{\tau}{1-\tau} \frac{B}{X\left(t^{\star}\right)}\right]+\frac{\tau-\tau}{1-\tau} \frac{f\left(t^{\star}\right)}{F\left(t^{*}\right)}\left[1-\frac{B}{X\left(t^{\star}\right)}\right]$ 


\section{Proposition 12:}

For capital gains taxation at the same rate, planned selling time is the same under constructive realization as under carryover. Planned cutting tine is greater under step up.

\section{Proof:}

Since $f(t)<0$, this follows immediately from (28).

Note that planned selling time is not the same as actual selling times. Under either step up or constructive realization an investor's heirs may plan to sell an asset at a different time than the original investor planned. This is because the heirs will have a different, higher basis which will cause them to plan to sell sooner than the original investor. They also will have a different mortality function which will, under step up also affect their planned selling time. It is easy to see from (27) that increases in either $\tau$ or $\tau_{d}$ will decrease the value of an asset.

The effects of Increases in $\tau$ on planned selling time are more complicated. Since planned selling time is the same under constructive realization as under carryover, $d t * / d \tau<0$ in both cases. Under step up $d t * / d \tau$ can be either positive or negative. If $B=0$, the selling tine will be greater under step up then if there were no taxation so $\frac{\partial t^{\star}}{\partial \tau}$ must be positive. On the other hand if $B$ is positive and $-\frac{f\left(t^{*}\right)}{F\left(t^{*}\right)}$ is very small, $\frac{\partial t^{*}}{\partial \tau}$ will be negative -- as it is when $\frac{f\left(t^{*}\right)}{F\left(t^{*}\right)}=0$. For simplicity we have given the analysis only for the case of wine, a similar analysis for trees shows that $u^{\star}$ satisfies

$$
\frac{V^{\prime}\left(u^{*}\right)}{V\left(u^{*}\right)}=r\left[1+\frac{\tau}{1-\tau} \frac{P}{V\left(u^{\star}\right)}+\frac{L}{V\left(u^{*}\right)(1-\tau)}\right]+\frac{\tau-\tau}{I-\tau} \frac{f\left(u^{*}\right)}{F\left(u^{*}\right)}\left[1-\frac{P}{V\left(u^{\star}\right)}\right]
$$




\section{REFERENCES}

Auerbach, A.J., "Wealth Maximization and the Cost of Capital," Ouarterly Journal of Economics, 93 (August 1979) 443-447.

Constantinides, G.M., "Capital Market Equilibrium with Personal Tax," Graduate School of Business, University of Chicago, 1979, Working Paper 33, revised, February 1980.

Constantinides, G.M. and M.S. Scholes, "Optimal Liquidation of Assets in the Presence of Personal Taxes: Implications for Asset Pricing," Journal of Finance, 35 (May, 1980), 439-52.

Feldstein, M. and J. Slemrod, "Inflation and the Excess Taxation of Capital Gains on Corporate Stock," National Tax Journal, 31 (June, 1978), 107-18.

Feldstein, M., J. Slemrod and S. Yitzhaki, "The Effects of Taxation on the Selling of Corporate Stock and the Realization of Capital Gains," Quarterly Journal of Economics, 94 (June, 1980), 777-91.

Feldstein, M. and S. Yitzhaki, "The Effects of tine Capital Gains Tax on the Selling and Switching of Common Stock," Journal of Public Economics, 9, (February, 1978), 17-36.

Lippman, S. A. and J. J. MCCall, "Progressive Taxation in Sequential Decisionmaking: Deterministic and Stochastic Analysis," Western Maragement Science Institute, University of California, Los Angeles, working Paper 304, August 1980.

Stiglitz, J. E., "Some Aspects of the Taxation of Capital Gains." Unpublished ms., 1981. 


\section{Appendix I - Frequentiy Used Notation}

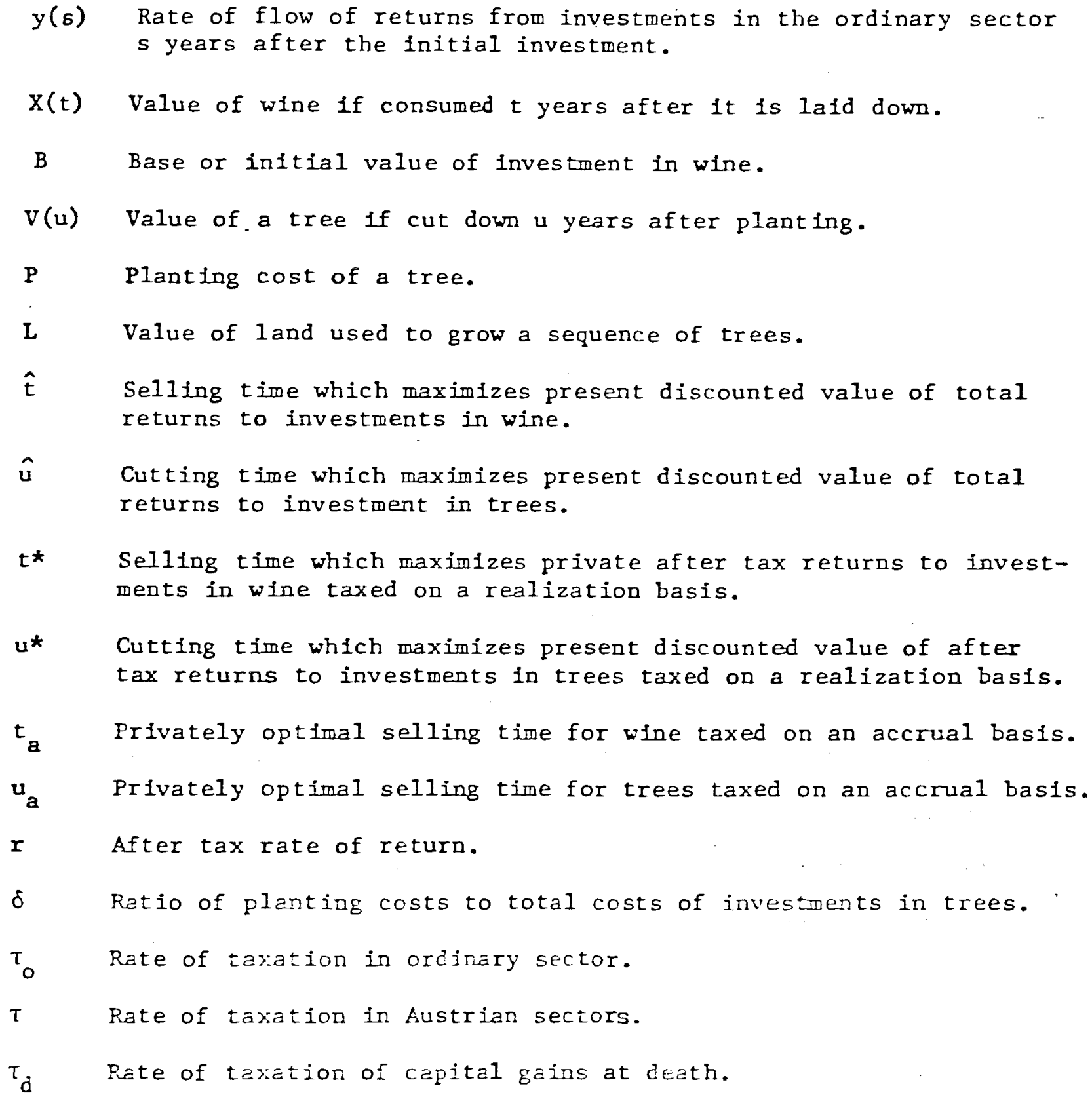




\section{APPENDIX II}

A. Let $A(\tau)=(1-\tau) \exp ^{r \tau_{a}(\tau /(1-\tau))}$ where $\tau_{a}$ is the solution to

$$
\frac{X^{\prime}\left(t_{a}\right)}{X\left(t_{a}\right)}=r /(1-\tau)
$$

1. Consider $X(t)=\mu t$. Then $t_{a}=(1-\tau) / r, A(\tau)=(1-\tau) e^{\tau} ; A(0)=1$, $A^{\prime}(\tau)=-\tau e^{\tau}<0$ and $A(1)=0$.

$$
\text { 2. Let } X(\tau)=\left\{\begin{array}{ll}
0 & \tau \leq d \\
\mu(\tau-d) & \tau>d
\end{array} \quad \text { for } d>\frac{1}{4 r}\right. \text {. }
$$

Then $r_{a}=d+(1-\tau) / r$ and

$$
A(\tau)=(1-\tau) \exp [\tau(1+(\operatorname{rd} /(1-\tau)))]
$$

$A(0)=1 ; \quad A^{\prime}(\tau)=\left[\frac{r d}{1-\tau}-\tau\right] \exp [\tau(1+(r d /(1-\tau)))]>0$, and

$\lim A(\tau)=\infty$

$\tau \rightarrow 1$

(This example may appear to violate the requirement that $X^{\prime}(\tau) / X(t)$ be decreasing as $X^{\prime}(t) / X(t)$ is undefined for $t<d$; however, since $X^{\prime}(t) / X(t)=\frac{1}{t-d}$, it is decreasing for $t>d$. Moreover, $X^{\prime}(t) / X(t)$ has but a single local maximum.) 
B.

1. Let $C(\eta)=\exp \left[(r+n) t_{a} \tau /(1-\tau)\right]$ where $t_{a}$ satisfies

$$
X^{\prime}\left(t_{a}\right) / X\left(t_{a}\right)=(r+\tau \eta) /(1-\tau)
$$

Let $X(t)=\mu t$. Then we know from example 1 of Appendix II.A that $\mathrm{C}(0)<(1-\tau)^{-1}$ for $\tau>0$ so that if $\mathrm{C}^{\prime}(0)>0$ the distortions induced by the capital gains tax are reduced by small increments in the rate of inflation. For this case, $\tau_{a}=(1-\tau) /(r+\tau \eta) ; C(n)=\exp [\tau(r+\eta) /(r+\tau \eta)]$, and $C^{\prime}(\eta)=C(\eta) r(1-\tau) \tau /(r+\tau \eta)^{2}$, so inflation at low rates reduces distortions. However, $\lim _{n \rightarrow \infty} C(\eta)=$ e and if $e>(1-\tau)^{-1}$ (or if $\tau<.632$ ), then high rates of inflation more than correct the distortions induced by the capital gains tax. Increases in inflation beyond the point where $C(\eta)=(1-\tau)^{-1}$ increase distortions.

2. For a more dramatic example of this effect, consider again the case where

$$
X(t)=\left\{\begin{array}{ll}
0 & t \leq d \\
\mu(t-d) & t>d
\end{array} \quad \text { for } d>\frac{1}{4 r} .\right.
$$

Then

$$
\tau_{a}=d+(1-\tau) /(r+\tau \eta)
$$

so that

$$
C(n)=\exp [(r+\eta) d \tau /(1-\tau)+(r+\eta) \tau /(r+\tau \eta)]
$$

It is easy to calculate that $\mathrm{C}^{\prime}(\eta)>0$. We showed in example 2 of Appendix II.A that $\mathrm{C}(0)>(1-\tau)^{-1}$ so increasing inflation exacerbates the distortions of the capital gains tax. 
3. For an example where $C^{\prime}(n)$ can be negative let $X(t)=\mu t+k$ where $k>0$. Then $t_{a}=\frac{(1-\tau)}{r+\tau \eta}-\frac{k}{\mu}$ and

$$
C(\eta)=\exp \left[\frac{(r+\eta) \tau}{r+\tau \eta}-\frac{k(r+\eta) \tau}{\mu(1-\tau)}\right]
$$

It is easy to show that for $0<\tau<1$ sign $\left[C^{\prime}(\eta)\right]=\operatorname{sign}\left[\frac{(1-\tau) r}{(r+\tau \eta)^{2}}-\frac{k}{\mu(1-\tau)}\right]$.
For $k>\frac{\mu r(1-\tau)^{2}}{(r+\tau \eta)^{2}} C^{\prime}(\eta)<0$. 
C. Proposition A.1. The optimal cutting time of trees taxed on an accrual basis is decreasing in $\eta$, the rate of inflation.

Proof: The optimal cutting time $u_{a}$ solves

$$
\operatorname{Max}_{u} \frac{V(u) e^{-\left(\frac{r+T \eta}{I-T}\right) u}-P}{1-e^{-r u}}
$$

Assuming an interior solution, the first-order conditions imply

(A.1) $\quad P \leq V\left(u_{a}\right) e^{-\left(\frac{x+\tau \eta}{1-\tau}\right) u_{a}}$

(A.2) $\phi\left(u_{a}, \eta, \tau\right)=\left\{\left[V^{\prime}\left(u_{a}\right) e^{-\left(\frac{r+\tau \eta}{I-\tau}\right) u_{a}}-v\left(u_{a}\right)\left(\frac{r+\tau \eta}{1-\tau}\right) e^{-\left(\frac{r+\tau \eta}{1-\tau}\right) u_{a}}\right]\left[1-e^{-r u_{a}}\right]\right.$

$$
\left.-\left[V\left(u_{a}\right) e^{-\left(\frac{r+\tau \eta}{1-\tau}\right) u_{a}}-P\right] r e^{-r u_{a}}\right\} \div\left(1-e^{-r u_{a}}\right)^{2}=0 \text {. }
$$

Thus, $\frac{d u_{a}}{d \eta}=\frac{-\frac{\partial \phi}{\partial \eta}}{\frac{\partial \phi}{\partial u_{a}}}$ and, since $\frac{\partial \phi}{\partial u_{a}}<0$ from the second-order conditions,

$$
\begin{aligned}
\operatorname{sign} \frac{d u_{a}}{d \eta}=\operatorname{sign} \frac{\partial \phi}{\partial \eta}= & \operatorname{sign} v\left(u_{a}\right)\left\{\left(e^{-r u_{a}}-1\right)\left[\frac{v^{\prime}\left(u_{a}\right) u_{a}}{v\left(u_{a}\right)}+1\right]\right. \\
& \left.+\frac{u_{a}}{1-\tau}\left[r\left(1-\tau e^{-r u_{a}}\right)+\eta \tau\left(1-e^{-r u_{a}}\right)\right]\right\}
\end{aligned}
$$

Rearranging the first-order condition (A.2), we find that

$$
\begin{aligned}
\left(\frac{v^{\prime}\left(u_{a}\right) u_{a}}{v\left(u_{a}\right)}+1\right)\left(e^{-r u_{a}}-1\right) & +\frac{u_{a}}{1-\tau}\left[r\left(1-\tau e^{-r u_{a}}\right)+\eta \tau\left(1-e^{-r u_{a}}\right)\right] \\
& =\frac{u_{a}}{v\left(u_{a}\right)} \operatorname{Pr} e^{-r u_{a}} e^{\left(\frac{r+\tau \eta}{1-\tau}\right) u_{a}}+e^{-r u_{a}}-1 .
\end{aligned}
$$

Thus,

$$
\operatorname{sign} \frac{d u_{a}}{d \eta}=\operatorname{sign}\left\{\frac{u_{a}}{v\left(u_{a}\right)} \operatorname{Pr} e^{-r u_{a}} e^{\left(\frac{r+\tau \eta}{1-\tau}\right) u_{a}}+e^{-r u_{a}}-1\right\}
$$


From (A.1) we know that $P \leq V\left(u_{a}\right) e^{-\left(\frac{r+\tau \eta}{1-\tau}\right) u_{a}}$, which implies

(A.3) $\quad \frac{u_{a}}{v\left(u_{a}\right)} \quad P r e^{-r u_{a}} e^{\left(\frac{r+\tau \eta}{I-\tau}\right) u_{a}}+e^{-r u_{a}}-1 \leq\left(u_{a} r+1\right) e^{-r u_{a}}-1$.

The right-hand side of (A.3) attains a maximum over $u_{a} r \geq 0$ when $u_{a} r=0$. At this point $\left(u_{a} x+1\right) e^{-r u_{a}}-1=0$. Thus, $\frac{d u_{a}}{d n} \leq 0$. 
D.

In this section, we show that with wine taxed on a realization basis, at low rates of inflation an increase in $\eta$ can increase or decrease selling time. We give examples where $\left.\frac{d t^{*}}{d \eta}\right|_{\eta=0}$ is greater than, less than, and equal to zero.

$$
\text { 1. Let } x(t)=\left\{\begin{array}{ll}
0 & t \leq d \\
\mu(t-d) & t>d
\end{array} \quad \text { where } d>0 .\right.
$$

Then from (21), with $\eta=0, t^{*}=\frac{l}{r}+d-\frac{\tau}{1-\tau} \frac{B}{\mu}$ and from (22) and (23) $W^{*}(\tau, 0)=\frac{\mu}{r}(1-\tau) e^{-1-d r+\frac{r \tau}{(1-\tau) \mu}}$. From (24) this implies that

$$
\operatorname{sign}\left[\left.\frac{d t^{*}}{d \eta}\right|_{\eta=0}\right]=\operatorname{sign}\left[r d-\frac{r \tau}{(1-\tau)} \frac{B}{\mu}+\tau e^{-1-d r+\frac{r \tau B}{(l-\tau) \mu}}\right] .
$$

Inserting the condition $B=W^{*}(\tau, 0)$ from $(22)$, we see that the right-hand side of the above equation equals sign $[r d]$. Since $r d>0, \frac{d t^{*}}{d \eta} \eta_{\eta=0}>0$.

2. Let $X(t)=\mu t+c$ where $c \geq 0$. Setting $\eta=0,(21)$ implies

that $t^{*}=\frac{1}{r}-\frac{C}{\mu}-\frac{\tau}{1-\tau} \frac{B}{\mu}$, and from (22) and (23),

$$
W^{*}(\tau, 0)=\frac{\mu(1-\tau)}{r} e^{-1+\frac{r C}{\mu}+\frac{r \tau B}{(1-\tau) \mu}} .
$$

Inserting this value of $t^{*}$ into (24) and setting $\eta=0$, we find

$$
\operatorname{sign}\left[\left.\frac{d t^{*}}{d \eta}\right|_{\eta=0}\right]=\operatorname{sign}\left[-\frac{c r}{\mu}-\frac{\tau r B}{(1-\tau) \mu}+\tau e^{-1+\frac{c r}{\mu}+\frac{\tau r B}{(1-\tau) \mu}}\right]
$$

Setting $B=W^{*}(\tau, 0)$, the right-hand side of this equation becomes

$\operatorname{sign}\left[-\frac{c r}{\mu}\right]$. Thus, if $c$ equals zero $\left.\frac{d t^{*}}{d \eta}\right|_{\eta=0}=0$, while if $c$ is greater than zero, $\left.\frac{d t^{*}}{d r_{i}}\right|_{n=0}<0$. 
E. Proposition A.2. For trees taxed at realization, the optimal cutting time, $u^{*}$, is increasing in $\eta$.

Proof: An investor with a plot of land which can support one tree forever chooses to cut each tree planted after u* years, where u* solves

$$
\begin{aligned}
& \operatorname{Max}_{u}-P+\sum_{i=1}^{\infty} e^{-r u_{i}}\left[V(u)(1-\tau)+\tau P e^{-\eta u}-P\right] \\
& =\operatorname{Max}_{u} \frac{V(u)(1-\tau)+P\left[\tau e^{-\eta u}-e^{r u}\right]}{e^{r u}-1}
\end{aligned}
$$

Assuming an interior solution, a first-order condition for this problem is

$$
\begin{aligned}
& \phi\left(u^{\star}, n, \tau\right)=\left\{\left[(1-\tau) V^{\prime}\left(u^{*}\right)-\left(r e^{r u^{*}}+n \tau e^{-n u^{*}}\right) P\right]\left[e^{r u^{*}}-1\right]\right. \\
& \left.-r e^{r u^{*}}\left[(1-\tau) V\left(u^{*}\right)-\left(e^{r u^{*}}-\tau e^{-\eta_{u *}}\right) P\right]\right\} \div\left(e^{r u^{*}}-1\right)^{2}=0 .
\end{aligned}
$$

Thus $\frac{d u^{\star}}{d \eta}=\frac{-\frac{\partial \phi}{\partial \eta}}{\frac{\partial \phi}{\partial u^{\star}}}$ and, since $\frac{\partial \phi}{\partial u^{\star}}<0$ from the second-order conditions,

$$
\operatorname{sign} \frac{d u^{*}}{d \eta}=\operatorname{sign} \frac{\partial \phi}{\partial \eta}=\operatorname{sign}\left\{\left[(r+\eta) u^{*}-1\right] e^{r u^{*}}+\left(1-\eta u^{*}\right)\right\}
$$

Rearranging, we find that

$$
\begin{aligned}
& {\left[(r+\eta) u^{*}-1\right] e^{r u^{*}}+\left(1-\eta u^{*}\right)=\eta u^{*}\left(e^{r u^{*}}-1\right)+\left(r u^{*}-1\right) e^{r u^{*}}+1 \geq} \\
& \geq \eta u^{*}\left(e^{r u^{*}}-1\right) \geq 0 .
\end{aligned}
$$

Thus $\frac{d u^{*}}{d \eta} \geq 0$ 